thickly studded with nodules, which were rather larger than those in the left lung, several of them being half an inch in diameter. The rigbt pleura was quite normal, the white colour of the nodules, which were superficially situated, being apparent through it; these projected from the surface of the lung, their free surfaces being flattened. The pulmonary tissue surrounding the cancerous masses was quite healthy. The bronchial glands were enlarged, hard, and infiltrated. The brain, liver, kidneys, and all the other organs appeared to be quite healtby.

Remarks. - The absence of any family history of cancerous diathesis, the want of physical signs, and the obscurity of the symptoms, render this case of considerable interest apart from its extreme rarity. The absence of dulness is explained by the fact that the air-cells surrounding the nodules were permeable to air, and therefore perfectly resonant on percussion. Moreover, Dr. Beigel states: "The tissues surrounding the cancerous nodules lose their contractility, and would give a tympanitic sound, if its tympanitic character were not injured by the solid nature of the newly-formed nodules." The lack of symptoms indicating extensive disease of the lungs is also accounted for by the normal condition of the lung-substance surrounding the nodules. Dr. Bennett asserts that these nodules push aside the surrounding tissues, and may remain for an indefinite time without exciting inflammation or causing derangement of function. Although in this case some malignant affection was suspected, it was solely from the emaciated and cachectic appearance of the child.

I may add that the mother improved rapidly under treatment, and left the hospital in six weeks almost well.

Guildford.

\section{DESCRIPTION OF A NEW EUSTACHIAN CATHETER.}

\section{By ALEXANDER MORISON, M.B. EDIN.}

Ir has been truly remarked that the inventive ingenuity of a surgeon in the production of new instruments for old purposes stands, as a rule, in an inverse ratio to his operative dexterity; and $\mathrm{my}$ excuse for introducing to the notice of the profession a modification of the Eustachian catheter usually known as Kramer's must rest in the fact that, even after considerable experience in the use of this instrument, and after one has successfully catheterised a given case at one sitting, before hitting the faucial orifice of the Eustachian tube on subsequent occasions time is not unfrequently lost, and the patient's nares and throat are rendered irritable by repeated endeavours to place the catheter in position. To obviate these inconveniences, I have had constructed by Messrs. Arnold and Sons, of West Smithfield, the instrument to be described.

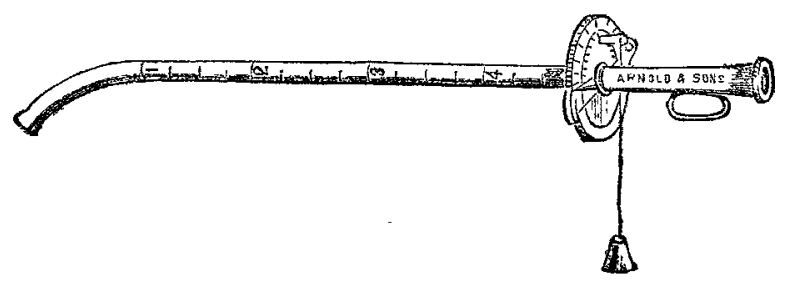

Note,- The woodcut does not illustrate the text aright owing to a blunder on the part of the engraver, $-A$. M.

The most usual form of silver Eustachian catheter is graduated in inches and eighths of an inch (not a new idea); and about an inch and a half from the dilated end of the tube there is a furrow for the reception of a silver circlet, graduated from $0^{\circ}$ to $90^{\circ}$, and having a miniature plumb depending from it to mark the perpendicular. This circlet can be removed and fitted on to any number of catheters constructed with the aforesaid groove. On the same side as the curve of the instrument a spike or indicator springs from the catheter immediately behind the circlet, so that when the instrument is turned into position, by finding the perpendicular with the plumb, the exact angle at which the catheter is placed is indicated upon the graduated circlet. By means of this instrument, therefore, two points are de- termined-namely, the depth at which the orifice of the Eustachian tube is situated from the external nares, and the number of degrees the catheter has to be revolved in order to enter that orifice. The angle should be taken not merely when air enters the tympanic cavity, as determined by the diagnostic tube, but when it enters in the fullest stream. The above points being noted at a first sitting, one has no difficulty in quickly placing the instrument in position on any subsequent occasion.

I have practically tested the utility of this catheter, and can imagine its proving useful to the expert, and rendering catheterisation of the Eustachian tube a very simple process to those who have less frequently to perform that operation.

Canonbury, N.

\section{A : Aftirror}

\section{HOSPITAL PRACTICE, BRITISH AND FOREIGN.}

Nulla antem est alia pro certo noseendi via, nisi quamplurimas et morboram et dissectionum historias, tum aliorum, tum proprias collectas habere, et inter se comparare-MonGAQNI De Sed.et Caus. MMorb., lib. iv. Proomium.

\section{KING'S COLLEGE HOSPITAL.}

FRACTURE OF THIGH, OF BOTH CONDYLES AND OF THF BODY OF LOWER JAW, AND OF THE THYROID AND CRICOID CARTILAGES; LARYNGITIS ; LARYNGOTOMY; PNEUMONIA; DEATH.

\section{(Under the care of Mr. Royes BeLu.)}

For the notes of this extremely interesting and complicated case we are indebted to Mr. Duncan, surgical registrar.

Thomas W-, aged twenty-five, admitted into Fisk ward, Sept. 11th, 1876, for injuries resulting from a fall. The patient was employed at the New Law Courts. Whilst. in the act of stepping from one part of the scaffolding to another, he missed his footing, and fell a distance of thirty feet. He was picked up in a state of insensibility, and brought to the hospital, where it was found that he had sustained a fracture of the thigh, and other injuries. About an hour afterwards he had recovered consciousness somewhat. He was bleeding from the left ear and nose; the pupils were equal, and reacted to light. A long Liston splint was applied temporarily to the thigh. The bæmorrhage from the left ear and nose had ceased at night; that from the ear amounted to about half an ounce. No discharge of serous fluid succeeded the hæmorrhage.

Next day he had completely recovered consciousness, but he could not hear a watch ticking on the left side, even placed close to the ear. The pupils were equal, and reacted to light. Passed urine freely.

There was a deep cut on the point of the chin, extending inwards for about an inch, but not leading down to the lower jaw. There was also a superficial cut on the middle of the lower lip. On looking into the mouth, the lower jaw was seen to be bodily displaced backwards for at least a quarter of an inch behind the upper. There was also a slight lateral displacement to the left side, so that the right central incisor tooth occupied the middle line. The body of the jaw was freely movable on an antero-posterior plane. As the fracture could not be precisely made out, chloroform was administered, and a fracture was found to have occurred through the neck of the lower jaw on the left side. There was marked crepitus here. At the corresponding site on the opposite side, a peculiar crepitus, as if some muscle were interposed between two bony surfaces, was also present. No abnormal movement or crepitus was obtainable through the right half of the body of the bone. No apparent injury to the left external auditory neatus.

The patient had no dyspnca or hæmoptysis, nor did he complain of pain, or draw any attention to his laryngeal region. Th voice was somewhat husky. The right thigh was fractur at the junction of the middle and lower 
thirds. The upper fragment was rotated outwards, whilst the lower was drawn up behind and to the inner side of the upper, so that there was shortening to the extent of an inch and a half; and the upper end of the lower fragment also projected backwards into the ham. A considerable quantity of blood was evidently effused around the ends of the fragments, and there was a slight superficial excoriation of the skin here, but no bruising of the integuments was present.

Temperature on evening of admission $100^{\circ}$; next morning $98 \cdot 2^{\circ}$; pulse 80 . On the 12 th the long splint was readjusted, and the normal length of the thigh apparently restored; extension was also kept up by a weight attached to the end of the foot-piece.-At $5.25 \mathrm{P} \mathrm{M}$. the patient had a rigor lasting fifteen minutes; temperature during the rigor reached 104:4\% He sweated freely afterwards, and was sick four times.

Sept 13th.-There has been a recurrence of bleeding from the left ear to a slight extent. Deafness still continues; no dyspnoa. Feels generally much better. Morning temperature $99 \cdot 4^{\circ}$; evening $99 \cdot 2^{\circ}$.

14th.-Morning temperature $99 \cdot 6^{\circ}$. There is still slight intermittent bæmorrhage from the left ear. General condition good.

15th.- In much the same condition. Hæmorrhage from the ear has ceased.

16th.-This morning a fracture was discovered through the right side of the body of the jaw, close to the sfmphysis. Crepitus and abnormal mobility were marked. These symptoms could not be obtained previously. He complains for the first time of difficulty of breathing. Expectorates some quantity of phlegm, not tinged with blood. Did not complain of any pain in the larynx. Chest examined, and some subcrepitant rhonchi beard scattered over the bases. Morning temperature $102 \cdot 2^{\circ}$; evening $101 \cdot 4^{\circ}$.

17th.-Morning temperature $102^{\circ}$. An exacerbation of the dyspncea came on suddenly about 11 A.M., with pains in the larynx and stridulous breathing. The dyspnœa increased during the day. Laryngotomy was performed at 10 P.Mr. by Mr. Ground, the house-surgeon, with immediate relief to the patient. Previously to the operation very little air was heard entering the lungs. Temperature was then $101 \cdot 2^{\circ}$.

18th.-Feels much easier; respiration free. Morning tem perature $100^{\circ} 6^{\circ}$; evening, $1034^{\circ}$.

$19 \mathrm{th}$.-Is very restless this morning. Temperature $102.4^{\circ}$ Respiration rapid; perspiring freels; subcrepitant rhonchi over the lower lobes of both lungs. The deafness of the left ear has passed off. The fracture of the thigh has become displaced again, from the restlessness of the patient; the leg was accordingly placed on a MoIntyre splint, continuous extension being kept up by a weight attached to the foot-piece. Evening temperature 104:2

20 th.-At 950 A.M. had a rigor, during which the temperature was $1042^{\circ}$. Began to perspire at 10.30 , and when the temperature was $105^{\circ}$ crepitant rhonchus and dulness were found to be present over right base in the afternoon; great increase of the dyspncea.

21 st.-The dyspnoa gradually increased, and the patient died at 4 P.M.

Post-mortem.-The lower jaw was found to be fractured just below the condyles on both sides. There was also a fracture through the right half of the body of the bone, descending vertically just external to the incisor teeth for about balf the depth of the bone, and then sloping off at an obtuse angle till the lower margin was reached, in such a manner that the right half dovetailed into the left half of the body of the bone. This fracture had evidently been impacted on the patient's admission. On opening the larynx the mucous membrane as far as the vocal cords was found much swollen. There were also some patches of dirtylooking lymph lining it. The thyroid cartilage was fractured linearly in a vertical direction. The cricoid had also sustained a sljgbt fracture, whilst an internal lamina was separated in a necrosed state from the rest of the cartilage. Two small abscesses were found in the neighbouring soft parts externally. The mucous membrane was ulcerated opposite the cricoid. The right thigh was fractured at the junction of the middle and lower thirds. A considerable quantity of purulent fluid surrounded the broken ends. On sawing off the lower portion of the upper fragment, the periosteum was seen to be stripped off from the bone, whilst a mass of fungous granulations projected from and filled the medullary cavity. There was no fracture of the base or of any part of the skull. The membrana tympani was intact on the left side. A grumous mass of dried blood lay in the left external auditory meatus. The left lower lobe of the lung was congested, and floated in water. The right lower lobe was in a state of commencing hepatisation.

\section{WEST LONDON HOSPITAL.}

RETENTION OF URINE AND PERINEAL ABSCESS FROM STRICTURE OF THE ORETHRA； INTERNAL URETHROTOMY TEN DAYS AFTER THEIR RELIEF ; GOOD RESULT. (Under the care of Mr. Temvan.)

EDWARD $\mathrm{H} \longrightarrow$, a thin, wiry-looking labourer, forty-five years old, was admitted into the hospital on July 28th, suffering from retention of urine and a large perineal abscess. The patient stated that he had had two attacks of gonorrhœa, the first one as far back as thirty years ago. For many years he had experienced difficulty in making water, and twelve years ago had retention of urine, which was relieved by medicines and a hot bath, the surgeon not being able to pass an instrument. The patient bad been seen a few times before his admission by Mr. Angove, the housesurgeon, who had advised him to enter the hospital for operation. When admitted with retention, on July 28 th the perineum was much swollen, and there was distinct fluctuation, but the tumefaction was limited to the perineum, and did not affect the scrotum or penis. Although the man's temperature was up to $102^{\circ}$, there was but little constitutional disturbance, and he was calm and collected. $\mathrm{Mr}$. Angove passed a No. 2 silver catheter, and relieved the relention. Mr. Teevan, on his arrival at 3 P.M., made an incision into the median line of the perineum, and let out about a quarter of a pint of pus, apparently not mixed with urine. The next morning Mr. Angove found the patient quite comfortable, and his temperature fallen to $99.2^{\circ}$. On August 8th Mr. Teevan divided the three strictures, two of which were in the penis, from before backwards, and passed No. 25 to show that the passage was clear. No catheter was retained in the bladder, and there was no bleeding or rigor af ter the operation. On August 12th, 16th, and 19th, No. 25 metal " bougie à ventre" was passed. The patient was afterwards taught to introduce a large French catheter for himself, and on August $23 \mathrm{rd}$ be left the hospital in all respects quite well, the urethra being perfectly watertight. He called at the bospital on Oct. 7 th, and passed No. 24 bougie with ease, although no instrument had been introduced for six weeks.

Mr. Teevan remarked that he had in this case deferred the operation because the retention had been relieved before he saw the case, and, beyond giving a free exit to the perineal abscess, there was no indication for the immediate performance of any kind of urethrotomy. It might be asked, inasmuch as the urethra admitted a small silver catheter, why had he not passed a slender staff into the bladder and done external urethrotomy?-thus opening the abscess and dividing the strictures at the same time. His answer would be, that the penile strictures could not have been attacked by external urethrotomy, and he had therefore performed internal urethrotomy when the constitutional disturbance had passed away and the parts were in a quiet condition. An operation was indicated in the case on account of the situation and character of the strictures. The nearer a contraction was to the meatus externus, the less amenable it was to dilatation and the less the risk attached to any cutting operation for its relief. The urethrotome he had used was a modification made by him of Sédillot's, and he believed it fulfilled every requirement.

\section{NORTH HERTS AND SOUTH BEDS INFIRMARY,} HITCHIN.

RUPTURE OF DIAPHRAGM AND PROTRUSION OF STOMACH INTO THORAX; RUPTCRE OF LIVER, ILIAC VEINS, AND JEJUNUM.

(Under the care of Mr. O. Foster and Mr. O. H. Foster.) For the notes of this case we are indebted to Mr. E. A. Praeger.

J. B-, while working in a brick-field, soon after twelve 